\title{
A EDUCAÇÃO PARA O SÉCULO XXI E A FORMAÇÃO DO PROFESSOR REFLEXIVO NA ENFERMAGEM
}

Josimerci Ittavo Lamana Faria ${ }^{1}$ Lisete Diniz Ribas Casagrande ${ }^{2}$

Faria JIL, Casagrande LDR. A educação para o século XXI e a formação do professor reflexivo na enfermagem. Rev Latino-am Enfermagem 2004 setembro-outubro; 12(5):821-7.

Neste estudo, apresentam-se abordagens de grandes estudiosos da educação dos últimos anos, discutindo-se os pressupostos da docência reflexiva neste novo século. Com ênfase na área profissional da enfermagem, são mostradas as tendências de formação, atuação e desenvolvimento de professores, quanto aos saberes e competências exigidos, a prática docente e aspectos da educação reflexiva do professor de enfermagem no Brasil. A análise da literatura, além do aprofundamento dos conhecimentos sobre a temática, permitiu desvelar a necessidade urgente de revitalização da docência universitária no enfoque reflexivo, com vistas a tornar os professores mais comprometidos e competentes para o exercício da sua profissão.

DESCRITORES: educação; enfermagem; docente de enfermagem

\section{EDUCATION FOR THE XXI CENTURY AND THE REFLEXIVE TEACHER'S FORMATION IN NURSING}

This study shows expert approaches to education in the last few years and discusses the premises of reflexive teaching in this new century. Emphasizing the area of professional nursing, we discuss tendencies in the formation, activities and development of teachers with respect to the required knowledge and abilities, the teaching practice and aspects of nursing teacher's reflexive education in Brazil. Besides providing a deeper knowledge about the subject, the literature review allowed us to reveal the urgent need to revitalize college teaching from a reflexive perspective, in order to increase teachers' commitment and competency for professional performance.

DESCRIPTORS: education; nursing; faculty, nursing

\section{LA EDUCACIÓN PARA EL SIGLO XXI Y LA FORMACIÓN DEL PROFESOR REFLEXIVO EN LA ENFERMERÍA}

En este estudio se exponen abordajes de grandes estudiosos de la educación en los últimos dos años, presentándose los presupuestos de la docencia reflexiva en el nuevo siglo. Con énfasis en el área profesional de enfermería, son mostradas las tendencias de la formación, actuación y desarrollo de los profesores, considerando los conocimientos y competencias exigidas, la práctica docente y aspectos de la educación reflexiva del profesor de enfermería en Brasil. El análisis de la literatura permitió descubrir la necesidad urgente de revitalización de la docencia universitaria en el enfoque reflexivo, con el propósito de aumentar el comprometimiento y las competencias de los profesores para el desempeño de su profesión.

DESCRIPTORES: educación; enfermería; docente de enfermería

\footnotetext{
${ }_{1}^{1}$ Doutoranda da Escola de Enfermagem de Ribeirão Preto, da Universidade de São Paulo, Centro Colaborador da OMS para o desenvolvimento da pesquisa em enfermagem, Professor Assistente da Faculdade de Medicina de São José do Rio Preto, e-mail: josiitta@ig.com.br; ${ }^{2}$ Professor Doutor da Faculdade de Filosofia, Ciências e Letras de Ribeirão Preto da Universidade de São Paulo, e-mail: Casagrande@netsite.com.br
} 
A EDUCAÇÃO PARA O SÉCULO XXI

$\boldsymbol{O}$ século XXI está em seus primeiros anos, e é evidente que os notáveis progressos científicos, tecnológicos e econômicos ocorridos, relacionados a diferentes aspectos da globalização, provocaram profunda mudança ideológica, cultural, social e profissional, revelada em fenômenos de exclusão social, persistindo as desigualdades de desenvolvimento no mundo. Diante dessa aceleração, os países que quiserem prosperar devem se comprometer com a educação e entender as transformações, porque elas vão ditar as competências, exigidas não só em conhecimentos e habilidades no trabalho, mas também relacionadas ao caráter e à personalidade ${ }^{(1)}$.

Um dos maiores desafios do século atual, onde as pessoas estão em busca de raízes e referências, está em aprender a viver juntos neste mundo globalizado, e a educação emerge como o grande trunfo, por possibilitar o desenvolvimento contínuo de pessoas e de sociedades. Em relatório encaminhado à UNESCO, a Comissão Internacional de Estudos sobre a Educação para este século sublinha que, para dar resposta ao conjunto de suas missões, a Educação deve estar organizada em torno de quatro aprendizagens fundamentais: aprender a conhecer (adquirir cultura geral ampla e domínio aprofundado de um reduzido número de assuntos, mostrando a necessidade de educação contínua e permanente), aprender a fazer (oferecendo-se oportunidades de desenvolvimento de competências amplas para enfrentar o mundo do trabalho), aprender a conviver (cooperar com os outros em todas as atividades humanas) e aprender a ser, que integra as outras três, criando-se condições que favoreçam ao indivíduo adquirir autonomia e discernimento ${ }^{(2)}$.

Para que a educação seja estruturada nesses quatro pilares do conhecimento, as finalidades do sistema educacional e as competências dos professores não podem ser dissociadas, de forma que a prática docente esteja em consonância com as finalidades da escola ${ }^{(3)}$.

Os conflitos educacionais da atualidade são identificados na forma como se manifestam no cotidiano escolar, no enfoque da organização da instituição e quanto a alunos e professores. Estudiosos de várias correntes filosóficas têm contribuído para aumentar a compreensão sobre a educação de jovens, indicando que os docentes devem cumprir o processo pedagógico de forma mais política, possibilitando maior encontro entre as percepções e visões de alunos e docentes, que repercutam em melhor qualidade de formação e atuação de ambos ${ }^{(4)}$.

Desde o final do século XX, tem sido amplamente discutida a Educação Transformadora, que deve ser feita em profunda interação educador-educando, voltada especialmente para a reelaboração dos conhecimentos e habilidades aprendidos e a produção de novos conhecimentos. Para tanto, deverão ocorrer ações como a reflexão crítica, a curiosidade científica, a criatividade e a investigação, dentro da realidade dos educandos, tendo o professor a responsabilidade de articular metodologias de ensino caracterizadas por variedade de atividades estimuladoras da criatividade dos alunos ${ }^{(5)}$.

Muitas escolas e os professores não têm conseguido acompanhar as profundas mudanças do mundo atual, o que tem provocado freqüentes debates e publicações sobre educação, nos diferentes níveis de ensino, discutindo-se tanto a premência de mudanças no projeto educativo das escolas, quanto de formação, atuação e desenvolvimento dos que nela ensinam ${ }^{(6)}$.

Há algum tempo temos nos preocupado com as questões que envolvem o ensino nessa área profissional, pois ela vem mostrando um modelo de educação muito semelhante a outras profissões da área da saúde, onde a atuação do professor é evidentemente instrumental, fundamentada basicamente em princípios e técnicas científicas, negligenciando-se aspectos de atitudes e valores éticos e políticos. No entanto, partindo do princípio que as Instituições de Ensino Superior (IES) são parcialmente responsáveis pela formação de cidadãos e profissionais competentes, tal perspectiva prática tem merecido maior discussão nos últimos anos, mostrandose que o ensino tradicional nas IES é concebido praticamente sem nenhuma sustentação conceitual e teórica na investigação educativa, propiciando a reprodução de vícios e mitos, empobrecimento do pensamento pedagógico e do interesse e estímulo de docentes e alunos. Já a prática educativa reflexiva tem buscado representar o novo papel que deve ser desempenhado na educação, com ênfase na investigação da própria prática, no processo interativo, no diálogo com a situação real, enfim, o professor como prático-reflexivo ${ }^{(7)}$.

Para o alcance da prática reflexiva, o professor deve ser capaz de organizar uma pedagogia construtivista, criar situações de aprendizagem, experimentar e corrigir, por intermédio do diálogo estabelecido com a sua realidade de trabalho, a sua atuação. Nessa perspectiva, estratégias de formação que propiciem a revelação da finalidade da 
aprendizagem, do conteúdo e das estratégias escolhidas, que levem o aluno a se conscientizar dos objetivos propostos, são importantes para o desenvolvimento do pensamento reflexivo e da autonomia ${ }^{(8)}$.

Há alguns anos, temos investigado a prática docente na enfermagem, na busca de contribuir para um ensino de maior qualidade nessa área profissional. Temos questionado, principalmente, se a formação, atuação e desenvolvimento de professores na enfermagem estão de acordo com as expectativas traçadas para a educação do século XXI, isto é, com espírito científico e pensamento crítico reflexivo, para que desenvolvam os saberes e competências essenciais à sua prática docente. Assim, buscamos, na revisão da literatura, aprofundar nossos conhecimentos sobre os assuntos que apresentamos a seguir.

Foram utilizadas, neste estudo, publicações dos últimos 10 anos de autores expoentes no assunto.

\section{TENDÊNCIAS ATUAIS NA FORMAÇÃO E DESENVOLVIMENTO PROFISSIONAL DO PROFESSOR UNIVERSITÁRIO}

Freqüentemente, verifica-se que, no centro dos debates e discussões sobre os rumos da educação, está a formação, o desempenho e o desenvolvimento profissional do professor. Nos tempos atuais, a docência universitária deve propiciar a formação do profissional cidadão, devendose alterar os projetos pedagógicos que privilegiam a formação de técnicos profissionais. Assim, deve haver condições de capacitação, qualificação e desenvolvimento do corpo docente, para que o processo de ensino aprendizagem seja mais efetivo, no que diz respeito à área pedagógica, à perspectiva político-social e à pesquisa ${ }^{(9)}$.

Os currículos, via de regra, são apontados como os grandes vilões da baixa qualidade no ensino superior. No entanto, essa situação está muito relacionada com falhas na formação dos professores universitários, o que compromete o seu desempenho. Apesar dessa constatação, pouca atenção tem sido voltada à formação e desenvolvimento de docentes de nível superior no Brasil $^{(10)}$

Grandes estudiosos da educação, ao discutirem a formação de professores e analisarem a prática pedagógica usual, recomendam uma nova articulação entre a teoria e a prática e propõem a reflexão como essência no processo de formação, atuação e desenvolvimento profissional de professores ${ }^{(7,11-13)}$. Esses autores reconhecem a grande contribuição de Deweynos estudos sobre formação de professores, pois seus estudos forneceram as bases conceituais da aprendizagem que ocorre pela experiência e pela observação e, em especial, a abordagem de formação reflexiva de professores sobre a sua prática.

A formação do professor, segundo a concepção reflexiva, pressupõe o seu desenvolvimento, para que seja capaz de ser autocrítico, de realizar uma análise do seu ensino e que seja capaz de adquirir competências cognitivas e relacionais. Assim, considerando os estudos de Pollard e Tann, destacam-se as seguintes ${ }^{(14)}$ :

- empíricas: para saber o que está acontecendo em uma classe, deve recolher e descrever dados, as situações, as causas e os efeitos;

- analíticas: necessárias para interpretar os dados descritivos, possibilitando inferir uma teoria;

- avaliativas: úteis para a emissão de juízos sobre eventos e resultados da educação;

- estratégicas: saber planificar a ação e antecipar a sua implementação de acordo com a análise feita;

- práticas: estar apto a estabelecer relações entre a análise e a prática, assim como entre os fins e meios para alcançar um bom efeito;

- comunicação: saber comunicar e partilhar suas idéias com outros colegas.

$\mathrm{Na}$ abordagem da docência reflexiva, são colocados em pauta os saberes e competências necessários aos professores, mostrados como campo novo para a pesquisa e ainda muito pouco explorado pelas ciências da educação ${ }^{(15)}$. Entende-se o saber docente como aquele formado pela associação, mais ou menos coerente, de saberes oriundos: da formação profissional, das ciências da educação e da ideologia pedagógica; os profissionais, transmitidos pelas instituições de formação de professores; os disciplinares, integrados à prática docente, por intermédio da formação inicial e contínua dos professores; os curriculares, das instituições escolares, concretamente explicitados sob forma de discursos, objetivos, conteúdos e métodos, e os experienciais, elaborados no exercício de sua prática docente, sendo validados pela própria experiência, incorporando-se à experiência individual e coletiva sob a forma de habitus e de habilidades, de saber-fazer e de saber ser ${ }^{(16)}$.

Muitos estudiosos da educação ressaltam que 
os professores podem adquirir os saberes da experiência por intermédio da reflexão sobre a própria prática cotidiana, mediada pelos pares. Tais saberes só serão reconhecidos na sua formação e desenvolvimento na prática docente, ao desenvolverem as competências ligadas ao trabalho como professor $^{(7,14-15,17-22)}$.

Para haver competência na prática docente, é preciso que esteja em jogo um repertório de recursos, como conhecimentos, capacidades cognitivas e capacidades relacionais. É difícil identificar, entre as competências de um professor, aquelas que são separáveis de sua pessoa, pois elas não se limitam àquilo que se adquire na formação profissional, já que toda história social e psicológica do sujeito é formadora ${ }^{(23)}$.

$O$ fato de os professores assumirem a sua formação contínua, é um dos sinais mais seguros para a profissionalização de seu ofício. A prática da autoformação deve resultar idealmente de uma prática reflexiva no desenvolvimento de seu ofício enquanto docente, constituindo-se em uma "fonte de aprendizagem e de regulação", tornando-se uma alavanca essencial na construção de novas competências e novas práticas ${ }^{(24)}$.

Nas últimas duas décadas, tem havido grandes movimentos sobre a atividade docente universitária no Brasil, revelando-se significados e valores até então pouco considerados, destacando-se que essa docência exige competências próprias e profissionalismo, com a finalidade de contribuir efetivamente para colocar na sociedade cidadãos corretos e profissionais competentes. Dessa forma, o ensino superior tenderá a reorganizar os seus currículos para atender a essas novas exigências, vitais ao exercício profissional competente. Tais reformulações devem sinalizar revisões em diversos aspectos, tais como: a flexibilização e a dinamização curricular, a formação profissional concomitante com a formação acadêmica, a ênfase na formação permanente, que deve ter início nos primeiros anos de graduação e persistir ao longo da vida profissional, a "revitalização da vida acadêmica pelo exercício profissional, a desestabilização de currículos fechados, acabados e prontos." Dentre as competências que deve ter um profissional para a docência de $3^{\circ}$ grau, destacam-se: domínio de determinada área do conhecimento, domínio na área pedagógica e o exercício da dimensão política ${ }^{(25)}$.

Dentre as competências do professor universitário, anteriormente descritas, são destacadas aquelas que deve ter um profissional completo para exercer a função docente ${ }^{(26)}$. Principalmente nos últimos anos, várias idéias vêm sendo colocadas e estão ganhando espaço no campo educativo, colocando-se em evidência o professor, a profissão, a profissionalidade docente, suas decisões e práticas pedagógicas. Mostra-se um esforço de evidenciar a figura do docente, propondo-se uma série de princípios teóricos ao ensino reflexivo, de se exercitar, na prática pedagógica do docente, uma atuação sistematicamente reflexiva, investigando-se como ensina, e a partir daí, melhorar paulatinamente seu modo de ensinar, representando uma estratégia de responsabilizá-lo por seu próprio desenvolvimento profissional ${ }^{(12)}$.

Buscando avançar na análise da formação do docente universitário, apresentamos, a seguir, algumas considerações sobre a prática reflexiva, que têm fomentado debates e mobilizado educadores, envolvendo as instituições formadoras e vários professores.

\section{A FORMAÇÃO DO PROFESSOR PARA A PRÁTICA DOCENTE REFLEXIVA}

A formação de professores, nas últimas décadas, tem sido desenvolvida sob influência da concepção de ensino como uma intervenção tecnológica, que concebe esse profissional como um técnico-especialista, o qual deve implementar, com rigor, normas e regras derivadas do conhecimento científico ${ }^{(7)}$.

Ao estudar a formação do professor reflexivo, notase que essa prática exige, além de formação específica, a possibilidade de desenvolver um estilo próprio de ensino, assumindo-o refletidamente, dentro de seu contexto de trabalho, evidenciando a necessidade de ir além dos pressupostos estabelecidos pela racionalidade técnica, que levaram à dicotomia e à ênfase nos aspectos teóricos do ensino ${ }^{(14)}$.

Educar pessoas do modo como o mundo precisa hoje demonstra a necessidade de um ensino voltado à liberdade e à autonomia, e não ao conformismo, como está explícito na "cultura reflexiva", que representa uma nova postura do docente e da escola, face às situações educativas $^{(4)}$.

Dentre as metáforas que emergiram sobre o papel do professor, cita-se o professor como prático reflexivo ${ }^{(11,27)}$. A importância da reflexão é evidenciada, enfatizando-se que, na prática profissional, o processo de diálogo com a situação deixa transparecer aspectos 
ocultos da realidade divergente e cria novos marcos de referência, novas formas e perspectivas de perceber e de reagir $^{(7)}$.

O conceito da prática pedagógica reflexiva, nos tempos contemporâneos, é o mais utilizado pelos pesquisadores e estudiosos do assunto, seja no que se refere à análise do trabalho docente, seja na formação de professores. Assim, sua popularidade tornou-se imensa, de forma que a conexão pensamento-ação/reflexãoprática, e a proliferação do termo prático-reflexivo têm percorrido as discussões sobre a temática da educação e as reformas no ensino, inclusive no Brasil ${ }^{(28)}$.

Uma das contribuições que se constitui em uma referência aos estudos, foi a proposta de programas de formação de professores com a utilização de momentos estruturados da prática pedagógica, com base em três idéias centrais: o conhecimento na ação, a reflexão na ação e a reflexão sobre a reflexão na ação ${ }^{(27)}$.

Esses três processos que se complementam em intervenção racional, compõem o pensamento prático do professor, com os quais ele enfrenta as diferentes situações no cotidiano educativo. Refletindo na e sobre a ação, o professor torna-se um investigador, afastando-se da racionalidade técnica e de regras derivadas de teorias externas, de prescrições curriculares, conhecendo mais profundamente as peculiaridades de seu trabalho e elaborando estratégias de ação mais adequadas ${ }^{(7)}$.

O docente que se opõe à racionalidade técnica, isto é, às ações submissas de aplicação de valores, normas e decisões político-curriculares, pode reelaborar seus saberes e sua prática de forma reflexiva ${ }^{(27)}$.

Consoante o exposto sobre a formação do professor para uma prática docente reflexiva, muitos estudiosos da educação voltam a sua atenção para a formação do professor-pesquisador, destacando a pesquisa como componente necessário à formação, desempenho e desenvolvimento de docentes. Sua importância é totalmente reconhecida, aparecendo em projetos, planos e leis governamentais, mas também são mostrados como evidentes o desconhecimento de como a pesquisa ocorre no cotidiano escolar e se ela efetivamente ocorre ${ }^{(29)}$.

No Brasil, poucas instituições de ensino superior têm se preocupado em desenvolver pesquisas, produzir e socializar conhecimentos, definindo-se mais por um sistema formador de profissionais para o mercado de trabalho. A pesquisa aparece na literatura internacional recente como uma prática fundamental na formação e no desenvolvimento profissional do professor, assim como nas propostas de reestruturação curricular.

De tudo que foi apresentado sobre a educação e a formação e desenvolvimento de professores, fica claro que, no novo século, não é mais possível formar profissionais com o ensino voltado à racionalidade técnica, tão contestada nos dias atuais.

Tal situação vem ocorrendo, com muita freqüência, em cursos da área da saúde, como o de Enfermagem, onde atuamos, que está requerendo ajustes em seu projeto pedagógico e na prática docente, de modo a propiciar melhores condições de formação aos alunos e de inserção no mercado de trabalho a seus egressos. Entendemos que, para propiciar um ensino de melhor qualidade, atendendo às necessidades de alunos e de professores, as novas formas de prática docente que estimulem o desenvolvimento do espírito científico e do pensamento reflexivo são características essenciais para atender às exigências contemporâneas do ensino de enfermagem. É sobre esse assunto que discorremos a seguir.

\section{O PROFESSOR REFLEXIVO NA ENFERMAGEM}

O trabalho docente contém múltiplos aspectos, sendo o seu dia a dia permeado de situações de intencionalidade e problematizações, de enfrentamento de atividades de ensino complexas, que produzem um cenário de tentativas sugestivas para renovar as estratégias usadas e que podem levar a um ensino inovador ${ }^{(19)}$. Dessa forma, é incongruente pensar na formação de um profissional reflexivo dentro de um cenário fundamentado na racionalidade técnica, pois esta não propicia a aproximação e reflexão diante de situações que surgem no decorrer do desenvolvimento profissional ${ }^{(20)}$.

$\mathrm{Na}$ tentativa de compreensão da prática docente reflexiva, constata-se que sua popularidade é grande, e são muitas as propostas de formação de professores ou de reestruturação curricular que utilizam esse conceito como elemento estruturador. Tratando-se especificamente da prática pedagógica de docentes de enfermagem brasileira, verifica-se que várias mudanças tornaram-se necessárias porque vinham reproduzindo um processo de ensino-aprendizagem sem se envolver muito com a aprendizagem significativa, fundamental para o desenvolvimento das pessoas e da sociedade. 
Acreditamos que, também na enfermagem, tem ocorrido o que, via de regra, ocorre quanto à docência no ensino superior, ou seja: organização curricular fechada, estanque, com disciplinas conteudísticas, com ênfase em assuntos técnicos, pouca abertura para outras áreas do conhecimento e interdisciplinaridade, pouco incentivo à pesquisa, com metodologia de ensino centrada em aulas expositivas, predomínio de cumprimento a um programa pré-estabelecido, avaliações por meio de provas e outros métodos tradicionais, e corpo docente constituído, ainda, por muitos professores que, mesmo titulados com mestrado ou doutorado, não possuem competências como educador, quanto à área pedagógica e à perspectiva políticosocial $^{(9)}$.

Nos últimos anos, a questão do sistema educacional, principalmente o universitário, tem sido destacada em eventos e publicações em várias partes do mundo, inclusive no Brasil, discutindo-se, particularmente, as condições vigentes na instituição escolar, seu projeto político-pedagógico, as características de seu corpo docente.

A atuação de docentes na enfermagem, numa perspectiva crítico-reflexiva, vem mobilizando algumas instituições de ensino, em especial de nível superior. $\mathrm{O}$ propósito é construir um modelo curricular, com um processo de formação articulado com o mundo do trabalho, que rompa com a dicotomia teoria/prática, com uso de estratégias pedagógicas inovadoras, com ensino contextualizado, proporcionando aprendizagem significativa e um futuro profissional mais crítico e compromissado com as questões profissionais e sociais $^{(30)}$.

Refletindo sobre o que é destacado no cenário educacional, a "cultura reflexiva" representa uma forma de educar pessoas como o mundo precisa, e depende muito do desenvolvimento da capacidade de auto-análise e reflexão dos professores, na busca de uma prática docente que considere tanto os aspectos de capacitação docente em conhecimentos e habilidades, mas também baseada na ética e no respeito à autonomia dos educandos.

O processo da prática reflexiva entre enfermeiros docentes, à semelhança do que ocorre em outras áreas profissionais, também tem merecido muitas discussões e algumas pesquisas em nosso meio, principalmente pela constatação da necessidade de transformações filosóficas e pedagógicas que venham a atender às expectativas da cultura no novo milênio, como está estabelecido na Lei de Diretrizes e Bases da Educação Nacional-Lei no 9.394/96
(LDB), que, entre as finalidades principais da educação superior, destaca a necessidade de se estimular a formação de profissionais com espírito científico e pensamento reflexivo.

Emanadas da LDB, surgem as diretrizes curriculares, que fornecem a cada área de formação profissional as bases para o exercício da profissão, definindo o perfil e competências a serem alcançados, ressaltando a necessidade da flexibilização dos currículos de graduação, de forma a permitir projetos pedagógicos inovadores, formando pessoas mais críticas, reflexivas, ativas, dinâmicas, adaptáveis às demandas do mundo do trabalho.

A nosso ver, a formação do professor reflexivo na enfermagem vai exigir uma redefinição em sua prática docente, em especial quanto ao desenvolvimento de certos saberes e competências que são destacadas como necessários no contexto do processo efetivo de ensinoaprendizagem ${ }^{(9)}$ :

- Uma interação entre professor-aluno voltada para a consecução dos objetivos educacionais propostos, de coresponsabilidade pelo aprendizado, de parceria, de equipe, de diálogo e respeito entre pessoas adultas.

- Alteração no espaço físico e circunstâncias do ambiente de ensino-aprendizagem, permitindo maior interação, participação, em espaços físicos que possam interessar e motivar os alunos.

- Redefinição dos objetivos da própria aula, para que se torne uma oportunidade de debate entre professor e alunos, com análise de leituras e informações trazidas pelo grupo. - Implantação de técnicas participativas, devendo o docente refletir sobre como introduzir novas técnicas que possibilitem a relação professor-aluno mais efetiva, onde ambos trabalhem e construam o conhecimento juntos, criando motivação para o envolvimento dos alunos.

- Alterar o processo de avaliação, que precisa ser pensado, planejado e realizado de forma integrada e coerente ao processo de ensino-aprendizagem proposto, assumindo o erro como oportunidade de crescer, de uma retroinformação, que provém do professor, do aluno, dos outros alunos, e de outros elementos que possam estar participando do processo.

\section{CONSIDERAÇÕES FINAIS}

A análise da literatura sobre os diferentes aspectos que envolvem a prática docente reflexiva, neste novo 
milênio, com enfoque na área da enfermagem, permitiunos desvelar vários aspectos neste contexto, aprofundando nossos conhecimentos sobre a temática de revitalização da docência universitária. Também propiciou a constatação de que nossa preocupação com o processo de formação do professor reflexivo na enfermagem está amplamente fundamentada, face às questões legais de cumprimento das diretrizes curriculares emanadas da LDB, além do compromisso que temos em formar profissionais competentes e cidadãos que possam contribuir para um mundo mais justo e para o prestígio da profissão.

Acreditamos, como explicitado pelos diferentes autores citados, na necessidade de formar professores

\section{REFERÊNCIAS BIBLIOGRÁFICAS}

1. James J. Pensando o futuro: as melhorias técnicas de liderança para uma nova era. São Paulo (SP): Futura; 1998. 2. Delors J. Educação: um tesouro a descobrir. Lisboa (PT): UNESCO/ASA; 1996.

3. Perrenoud P, Thurler MG. As competências para ensinar no século XXI: a formação dos professores e o desafio da avaliação. Porto Alegre (RS): Artmed; 2002.

4. Gomes JB, Casagrande LDR. A educação reflexiva na pósmodernidade: uma revisão bibliográfica. Rev Latino-am Enfermagem 2002; 10(5):696-703.

5. Freire P. Pedagogia da autonomia. $11^{\underline{a}}$ ed. Rio de Janeiro (RJ): Paz e Terra; 1997.

6. Alarcão I, organizadora. Escola reflexiva e nova racionalidade. Porto Alegre (RS): Artes Médicas; 2001.

7. Pérez Gómez APO. Pensamento prático do professor: a formação do professor como profissional reflexivo. In: Nóvoa A, organizador. Os professores e a sua formação. Lisboa (PT): Publicações Dom Quixote; 1992. p.95-114.

8. Alarcão I, organizadora. Formação reflexiva de professores: estratégias de supervisão. Lisboa (PT): Porto Editora, 1996. 9. Masetto M. Discutindo o processo ensino/aprendizagem no ensino superior. In: Marcondes E, Gonçalves EL, coordenadores. Educação médica. São Paulo (SP): Sarvier; 1998.

10. Gonçalves TO, Gonçalves TVO. In: Geraldi CMG, Fiorentini D, Pereira EMA, organizadores. Cartografias do trabalho docente: professor(a) - pesquisador(a). 2 $2^{a}$ ed. Campinas (SP): Mercado de Letras; 2000. p.105-134. (Coleção Leituras no Brasil)

11. Schön DA. The reflective practitioner. New York: Basic Books; 1983.

12. Zeichner KM. A formação reflexiva de professores: idéias e práticas. Lisboa (PT): Educa; 1993.

13. Perrenoud P. Construir as competências desde a escola. Porto Alegre (RS): Artmed; 1999.

14. Marcelo García C. Formação de professores: para uma mudança educativa. Portugal (PT): Porto; 1999.

15. Chakur CRSL. Desenvolvimento profissional docente: contribuições de uma leitura piagetiana. Araraquara (SP): JM Editora; 2001.

16. Tardif M. Saberes docentes e formação de professores. Petrópolis (SP): Vozes; 2002. reflexivos para a prática docente na enfermagem, para que eles sejam capazes de refletir sobre sua própria ação cotidiana como formadores, de comprometer-se com a pesquisa, com sua formação e com seu desenvolvimento profissional.

Por fim, esperamos que as informações e idéias emanadas dos grandes estudiosos sobre a educação contemporânea, algumas das quais apresentamos neste texto, sirvam para que outros docentes, atuantes na enfermagem ou em outra área profissional, possam refletir sobre sua prática ou para instigá-los na realização de pesquisas sobre a formação de docentes e profissionais reflexivos.

17. Schön DA. Formar professores como profissionais reflexivos. In: Nóvoa A. Os professores e a sua formação. Lisboa (PT): Dom Quixote; 1992.

18. Marcelo García C. A formação de professores: novas perspectivas baseadas na investigação sobre o pensamento do professor. In: Nóvoa A, organizador. Os professores e a sua formação. Lisboa (PT): Publicações Dom Quixote; 1992. p.51-76.

19. Pimenta SG. Formação de professores: identidade e saberes da docência. In: Pimenta SG, organizador. Saberes pedagógicos e atividade docente. São Paulo (SP): Cortez; 1999. p.15-33.

20. Campos S, Pessoa VIF. Discutindo a formação de professoras e professores com Donald Schön. In: Geraldi CMG, Fiorentini D, Pereira EMA, organizadores. Cartografias do trabalho docente: professor(a) - pesquisador(a). $2^{\underline{a}}$ ed. Campinas (SP): Mercado de Letras; 2000. p.183-206.

21. Gomes JB. Auto-avaliação: um caminho para a formação do profissional crítico-reflexivo na enfermagem. [tese]. Ribeirão Preto (SP): Escola de Enfermagem de Ribeirão Preto/ USP; 2001.

22. Feldman D. Ajudar a ensinar: relações entre didática e ensino. Porto Alegre (RS): Artmed; 2001.

23. Perrenoud P, Paquay L, Altet M, Charlier E. Formando professores profissionais: quais estratégias? Quais competências? Porto Alegre (RS): Artmed; 2001.

24. Perrenoud F. Novas competências para ensinar. Porto Alegre (RS): Artmed; 2000.

25. Masetto $M$, organizador. Docência na universidade. 4aㅡ ed. Campinas (SP): Papirus; 2002.

26. Vasconcelos MLMC. Contribuindo para formação de professores universitários: relato de experiências. In: Masetto $\mathrm{M}$, organizadores. Docência na universidade. $4^{\underline{a}}$ ed. Campinas (SP): Papirus; 2002.

27. Schön DA. Educando o profissional reflexivo. Porto Alegre (RS): Artmed; 2000.

28. Geraldi CMG, Fiorentini D, Pereira EMA, organizadores. Cartografias do trabalho docente: professor(a) pesquisador(a). $2^{\mathrm{a}}$ ed. Campinas (SP): Mercado de Letras; 2000.

29. Lüdke A, coordenador. O professor e a pesquisa. Campinas (SP): Papirus; 2001.

30. Chirelli MQ. O processo de formação do Enfermeiro crítico - reflexivo na visão dos alunos do Curso de Enfermagem da FAMEMA. [tese]. Ribeirão Preto (SP): Escola de Enfermagem de Ribeirão Preto/USP; 2002. 